\title{
PREVALENCE AND RECORD OF ALCOHOLISM AMONG EMERGENCY DEPARTMENT PATIENTS
}

\author{
Márcio Manozzo Boniatti, Luciano Passamani Diogo, Caroline Lorenzoni \\ Almeida, Michelle de Oliveira Cardoso
}

doi: $10.1590 / \mathrm{S} 1807-59322009000100006$

\begin{abstract}
Boniatti MM, Diogo LP, Lorenzoni AC, Cardoso MO. Prevalence and record of alcoholism among emergency department patients. Clinics. 2009;64(1):29-34.
\end{abstract}

OBJECTIVES: The purpose of this study was to investigate the prevalence of alcoholism among inpatients, to identify social and demographic factors associated with this prevalence and to determine its rate of recognition by the medical team.

METHODS: The study population consisted of all patients admitted to the emergency room at Hospital São Lucas, Porto Alegre, Brazil, between July and September of 2005. The data were collected in two steps: an interview with the patient and a review of the medical records to investigate the cases of alcoholism recorded by the medical team. The questionnaire consisted of questions concerning social and demographic data, smoking habits and Alcohol Use Disorders Identification Test.

RESULTS: We interviewed 248 patients. Twenty-eight (11.3\%) were identified as alcoholics. Compared to the patients with a negative Alcohol Use Disorders Identification Test value (less than 8), those with a positive Alcohol Use Disorders Identification Test were more likely to be male, illiterate and smokers. The medical records of $217(87.5 \%)$ patients were reviewed. Only $5(20.0 \%)$ of the 25 patients with a positive Alcohol Use Disorders Identification Test whose medical records were reviewed were identified as alcoholics by the medical team. The diagnosis made by the medical team, compared to Alcohol Use Disorders Identification Test, shows only a $20 \%$ sensitivity, $93 \%$ specificity and positive and negative predictive values of $29 \%$ and $90 \%$, respectively.

CONCLUSION: Alcoholism has been underrecognized in patients who are hospitalized, and, as such, this opportunity for possible early intervention is often lost. Key social and demographic factors could provide physicians with risk factors and, when used together with a standardized diagnostic instrument, could significantly improve the rate of identification of alcoholic patients.

KEYWORDS: Alcoholism; Inpatients; Prevalence; Diagnosis; Recognition.

\section{INTRODUCTION}

Alcohol consumption is common worldwide. In the United States, it is estimated that, among the adult population, $14 \%$ have a lifetime prevalence of alcohol dependence. ${ }^{1}$ A Brazilian multicentric study reveals that the prevalence of alcoholism ranges from 7.6 to $9.2 \%$ of the population. ${ }^{2}$ Abusive alcohol consumption is the main cause of disability among adult males in developed countries and is the fourth most prevalent cause in developing countries. ${ }^{3}$ In a study performed in Canada, abusive alcohol

Internal Medicine, Hospital São Lucas, Pontíficia Universidade Católica do Rio Grande do Sul - Porto Alegre/RS, Brazil.

Email: marciobt@terra.com.br

Tel.: 55513230.2000

Received for publication on June 28, 2008

Accepted for publication on September 22, 2008 consumption accounted for $3.1 \%$ of all deaths and $2.7 \%$ of all hospitalizations in $1995 .{ }^{4}$ It also has a major economic impact. The total annual cost estimated for alcohol consumption in the United States is 185 billion dollars, which has a great impact on not only direct health costs but also on overall productivity and other societal impacts. ${ }^{5}$

The prevalence of alcoholism is still greater among hospitalized patients. ${ }^{6-8}$ Several national and international studies have found a prevalence ranging from 7.4 to $48.0 \%$ of hospitalized patients. ${ }^{8-13}$ This large variation in the prevalence of alcoholism is largely attributed to the different methodologies used to define alcohol abuse or dependence and population heterogeneity.

Despite this high prevalence and the associated morbidity and mortality, diagnosing alcoholism as part of the medical history is often neglected by the medical team and, as a result, is often under-recorded in hospital records. A few 
studies have shown that identification of alcoholism by the medical team ranges from 7 to $89 \%$, depending on the department where the patient is hospitalized and the methodology used for diagnosis. ${ }^{8-11,14-16}$ There is evidence that suggests that use of questionnaires to screen patients would help identify alcoholic individuals and that brief interventions during the hospitalization would be effective in reducing alcohol consumption. ${ }^{10,16-19}$ Hospitalization is, therefore, an excellent opportunity to identify alcohol related disorders and initiate subsequent intervention.

The purpose of this study is to investigate the prevalence of alcoholism among hospital patients, to identify social and demographic factors associated with this prevalence, and to determine the rate of recognition of this problem by the medical team.

\section{MATERIAL AND METHODS}

This is a cross-sectional study carried out at Hospital São Lucas, Porto Alegre, Brazil. This hospital, which currently has 539 beds, receives patients from the public and private systems of several cities.

The study population consists of all patients who were admitted to the emergency room and subsequently remained in the hospital for at least 24 hours between July and September of 2005. The project protocol was evaluated and approved by the Institutional Ethics Committee. The following patients were excluded from the study: patients below the age of 15 years, patients who could not answer the interview (for instance, those on mechanical ventilation or mentally confused), and patients who refused to participate in the study. Written informed consent was obtained from all patients who participated in the study.

The data were collected in two steps: an interview with the patient and a review of the medical records. The interviews were performed in the emergency department during the first 48 hours after the patient was admitted by previously trained medical students. The questionnaire consisted of questions concerning social and demographic data, smoking habits and AUDIT (Alcohol Use Disorders Identification Test). ${ }^{20}$ AUDIT was developed by the World Health Organization and validated for use in the Portuguese language by Mendez et al. ${ }^{21}$ It consists of 10 questions concerning alcohol consumption in the last 12 months. The final score of this test ranges from 0 to 40 , with scores greater than or equal to 8 (the cutoff point generally used in research) indicating that the patient most likely has an alcohol-related disorder; this test has a sensitivity between 61 and $96 \%$ and a specificity between 84 and $96 \% .{ }^{22-}$ ${ }^{25}$ AUDIT was considered the gold standard for the diagnosis of alcoholism in this study. The mean length of the interviews was 6 minutes.
After the patient was discharged from the hospital, two researchers who were not involved in the interviews reviewed the patients' medical records. The purpose of this review was to examine the cases of alcoholism recorded by the medical team and the department in which the patient was hospitalized. A case was considered not recorded when the patient obtained a score above or equal to 8 in AUDIT and the record did not show a history of abusive alcohol consumption or similar terms (alcoholism, alcohol related disorders).

There was no contact between the researchers and the medical team, which, in turn, was blinded to the data collected in the interviews.

The terms 'positive AUDIT', 'alcoholic' and 'abusive alcohol consumption' are interchangeable for the purposes of this study.

For statistical analyses, Chi-squared and Mantel-Haensel tests were used for qualitative variables; the Mann-Whitney $\mathrm{U}$ test was used when the distribution of central tendency measures was not Gaussian in distribution. All the variables were dichotomized. Logistic regression was used to identify social and demographic variables that were independently associated with abusive alcohol consumption. $\mathrm{P}<0.05$ was considered a statistically significant number; all p-values were two-tailed. SPSS 12.0 software was used for the statistical analyses.

\section{RESULTS}

Of the 284 eligible patients who were hospitalized during the study period, $248(87.3 \%)$ were interviewed. Eight $(2.8 \%)$ patients refused to participate in the study, $11(3.9 \%)$ were physically unable to answer the questionnaire, and 17 $(6.0 \%)$ were excluded due to an altered sensory status.

The mean age of the population was $55.2 \pm 17.4$ years, $119(48.0 \%)$ were males, and $129(52.0 \%)$ were females. Most of the patients were white $(n=196 ; 79.0 \%)$, married ( $\mathrm{n}=135 ; 54.4 \%)$, had not completed elementary schooling ( $\mathrm{n}=109 ; 44.0 \%)$ and had a family income between one and five-times that of minimum wage ( $n=150 ; 60.5 \%$ ).

With regard to the study population's smoking habits, 45 (18.1\%) patients were smokers. Among the non-smokers, $111(54.7 \%)$ were former smokers, and $92(37.1 \%)$ of the patients had never smoked.

Twenty-eight (11.3\%) patients were identified as alcoholics. Among these patients with a positive AUDIT, 26 (92.9\%) had a score between 8 and 20, which corresponds to mild to moderate dependency. Only $2(7.1 \%)$ had a score higher than 20 (severe dependency). The mean score was significantly different between the patients with a positive AUDIT (mean 13.3; SD 4.8) and a negative AUDIT (mean 
Table 1 - Social and demographic characteristics of patients with a positive Alcohol Use Disorders Identification Test (AUDIT) and a negative Alcohol Use Disorders Identification Test

\begin{tabular}{|c|c|c|c|}
\hline Variables & $\begin{array}{l}\text { Positive AUDIT } \\
\mathrm{N}(\%)\end{array}$ & $\begin{array}{l}\text { Negative AUDIT } \\
\mathrm{N}(\%)\end{array}$ & $\mathrm{p}$ \\
\hline \multicolumn{4}{|l|}{ Age } \\
\hline$\leq 40$ & $6(13.6)$ & $38(86.4)$ & 0.780 \\
\hline$>40$ & $22(10.8)$ & $182(89.2)$ & \\
\hline \multicolumn{4}{|l|}{ Sex } \\
\hline Male & $20(16.8)$ & $99(83.2)$ & 0.015 \\
\hline Female & $8(6.2)$ & $121(93.8)$ & \\
\hline \multicolumn{4}{|l|}{ Race } \\
\hline Non-white & $10(20.4)$ & $39(79.6)$ & 0.037 \\
\hline White & $17(8.7)$ & $179(91.3)$ & \\
\hline \multicolumn{4}{|l|}{ Family income } \\
\hline 6 to 20 minimum wages & $5(13.9)$ & $31(86.1)$ & 0.804 \\
\hline Others & $23(10.8)$ & $189(89.2)$ & \\
\hline \multicolumn{4}{|l|}{ Schooling } \\
\hline Illiterate & $6(18.8)$ & $26(81.2)$ & 0.260 \\
\hline Some degree of instruction & $22(10.2)$ & $194(89.8)$ & \\
\hline \multicolumn{4}{|l|}{ Marital status } \\
\hline Single & $9(20.0)$ & $36(80.0)$ & 0.076 \\
\hline Others & $19(9.4)$ & $184(90.6)$ & \\
\hline \multicolumn{4}{|l|}{ Smoking } \\
\hline Yes & $11(24.4)$ & $34(75.6)$ & 0.005 \\
\hline No & $17(8.4)$ & $186(91.6)$ & \\
\hline
\end{tabular}

0.9; SD 1.6) $(\mathrm{p}<0.001)$.

The social and demographic characteristics of the patients with a positive AUDIT and a negative AUDIT are shown in Table 1. The alcoholic patients were slightly, but not significantly younger (mean $49.5 \pm 17.6$ years vs 55.8 \pm 17.3 years $)(\mathrm{p}=0.1)$ than the non-alcoholic patients. The characteristics of the patients who were identified as alcoholics by the medical team are shown in Table 2 .

Using a logistic regression analysis, a few variables proved to be independently associated with abusive alcohol consumption. Compared to patients with a negative AUDIT, those with a positive AUDIT were more likely to be male, illiterate and smokers (Table 3).

Among the 248 patients interviewed, the medical records of $217(87.5 \%)$ patients were reviewed. The other records were not found.

The medical team identified $17(7.8 \%)$ cases of alcoholism, and, when compared with the AUDIT outcomes, $12(70.6 \%)$ of them did not have a positive AUDIT.

Only $5(20.0 \%)$ of the 25 patients with a positive AUDIT whose medical records were reviewed were identified as alcoholics by the medical team. There was no difference in the incidence of identification that was dependent on the department in which the patient was hospitalized. Gastroenterology and Internal Medicine were the two departments where most of the alcoholic patients were hospitalized, and the medical staff of these departments

Table 2 - Identification of abusive alcohol consumption (correct or not) by the medical team and associated factors

\begin{tabular}{|c|c|c|c|}
\hline Variables & $\begin{array}{l}\text { Alcoholic according to } \\
\text { the medical team } \\
\mathrm{N}(\%)\end{array}$ & $\begin{array}{c}\text { Non-alcoholic or no } \\
\text { mention in medical records } \\
\mathrm{N}(\%)\end{array}$ & $\mathrm{P}$ \\
\hline Age & & & \\
\hline $\begin{array}{l}\leq 40 \\
>40\end{array}$ & $\begin{array}{l}4(10.3) \\
13(7.3)\end{array}$ & $\begin{array}{c}35(89.7) \\
165(92.7)\end{array}$ & 0.770 \\
\hline Sex & & & \\
\hline $\begin{array}{l}\text { Male } \\
\text { Female }\end{array}$ & $\begin{array}{c}15(14.6) \\
2(1.8)\end{array}$ & $\begin{array}{c}88(85.4) \\
112(98.2)\end{array}$ & 0.001 \\
\hline $\begin{array}{l}\text { Race } \\
\text { Non-white } \\
\text { White }\end{array}$ & $\begin{array}{c}3(7.0) \\
14(8.2)\end{array}$ & $\begin{array}{c}40(93.0) \\
157(91.8)\end{array}$ & 0.958 \\
\hline $\begin{array}{l}\text { Family income } \\
6 \text { to } 20 \text { minimum wages } \\
\text { Others }\end{array}$ & $\begin{array}{l}6(20.0) \\
11(5.9)\end{array}$ & $\begin{array}{c}24(80.0) \\
176(94.1)\end{array}$ & 0.021 \\
\hline $\begin{array}{l}\text { Schooling } \\
\text { Illiterate } \\
\text { Some degree of instruction }\end{array}$ & $\begin{array}{l}3(10.0) \\
14(7.5)\end{array}$ & $\begin{array}{c}27(90.0) \\
173(92.5)\end{array}$ & 0.913 \\
\hline $\begin{array}{l}\text { Marital status } \\
\text { Single } \\
\text { Others }\end{array}$ & $\begin{array}{l}6(15.0) \\
11(6.2)\end{array}$ & $\begin{array}{c}34(85.0) \\
166(93.8)\end{array}$ & 0.124 \\
\hline $\begin{array}{c}\text { Smoking } \\
\text { Yes } \\
\text { No }\end{array}$ & $\begin{array}{l}7(17.1) \\
10(5.7)\end{array}$ & $\begin{array}{c}34(82.9) \\
166(94.3)\end{array}$ & 0.034 \\
\hline
\end{tabular}


Table 3 - Results of logistic regression analyses for patients with a positive Alcohol Use Disorders Identification Test

\begin{tabular}{lcc}
\hline Risk factor & OR & P \\
\hline Age $\leq 40$ & 1.401 & 0.589 \\
Sex: male & 2.729 & 0.033 \\
Race: non-white & 0.418 & 0.073 \\
Family income 6 to 20 minimum wages & 1.251 & 0.705 \\
Illiterate & 3.228 & 0.042 \\
Marital status: single & 1.481 & 0.507 \\
Smoker & 3.815 & 0.005 \\
\hline
\end{tabular}

Table 4 - Results of logistic regression analyses for patients identified as alcoholics by the medical team

\begin{tabular}{lcc}
\hline Risk factor & OR & $\mathrm{p}$ \\
\hline Age $\leq 40$ & 0.922 & 0.919 \\
Sex: male & 8.456 & 0.007 \\
Race: non-white & 1.502 & 0.570 \\
Family income 6 to 20 minimum wages & 2.846 & 0.087 \\
Illiterate & 2.313 & 0.282 \\
Marital status: single & 3.764 & 0.065 \\
Smoker & 2.715 & 0.082 \\
\hline
\end{tabular}

identified only $25.0 \%$ and $14.3 \%$ of the patients with a positive AUDIT, respectively. Table 4 shows the association between the social and demographic characteristics and the identification of abusive alcohol consumption (independent of the diagnosis being correct or not) by the medical team.

The mean AUDIT score among the patients identified as alcoholics (mean $5.9 \pm 8.7$ ) was significantly higher than that of the patients who had not been identified (identified as non-alcoholics or no mention of alcohol consumption in the medical records) (mean $2.1 \pm 3.8)(\mathrm{p}=0.05)$. The diagnosis made by the medical team, compared to AUDIT, shows a $20 \%$ sensitivity, $93 \%$ specificity and positive and negative predictive values of $29 \%$ and $90 \%$, respectively.

\section{DISCUSSION}

The prevalence of alcoholism among the hospitalized patients in this study is at the lower limit of the variation of prevalence described in the international literature,,$^{8,10-13}$ but it approaches the prevalence of $13 \%$ that was found at another Porto Alegre hospital in a 1998 study. ${ }^{9}$

It only took an average of 6 minutes to apply the questionnaire, and $87.3 \%$ of the eligible patients agreed to participate in the study. Together, these figures confirm that it is possible to quickly investigate if the patients who come to emergency room have alcoholic tendencies, since it does not require much time and the patients are generally cooperative when asked. These findings had already been verified by Horn et al. ${ }^{12}$

Most of the alcoholic patients $(92.9 \%)$ in our study population were found to be mildly to moderately dependent (AUDIT between 8 and 20). There is evidence showing that interventions to reduce alcohol consumption have a greater impact on this patient subgroup. ${ }^{26-28}$ For example, Moore et al. found that hospital patients who were identified as alcoholics in screening performed by the medical team responded favorably to brief interventions (for instance, informing them of the diagnosis, advising them to stop drinking and making an appointment with an alcoholism specialist). ${ }^{10}$ Additionally, Gentilello et al. reported positive results for brief interventions at a trauma center, concerning the reduction of alcohol consumption and the reduction of risk of being readmitted for trauma. ${ }^{19}$ For these reasons, it seems logical that using an instrument with a greater capacity to identify at risk individuals within the emergency room patient population, as opposed to the traditional medical approach that has a low sensitivity, would allow for the initiation of early intervention that may provide more positive outcomes for individuals with mild to moderate dependency on alcohol.

There were significant social and demographic differences among the patients with a positive AUDIT and a negative AUDIT. The former are more likely to be male, illiterate and smokers. These differences have been described in other studies. Chen et al. found a higher prevalence of alcoholism among males, smokers, people who were younger and had a lower level of education. ${ }^{11}$ Another study reported a 2.7 -fold higher probability of alcoholism among males and a 2.4-fold higher probability of alcoholism among smokers. ${ }^{12}$ The patient's race may also influence the probability of alcoholism. Smothers et al. found that the rate of alcoholism is higher among black patients (13.1\%) than among the others $(6.6 \%) .{ }^{13}$ Being unmarried is another previously described risk factor. ${ }^{12,13}$

The association between alcohol consumption and tobacco use has also been described in the literature. ${ }^{29,30} \mathrm{It}$ was suggested that the greater the nicotine dependence is, the higher the alcohol consumption. ${ }^{31,32}$ In some studies, smoking has been defined as the main risk factor for alcoholism among hospitalized patients. ${ }^{11-13}$ The results of the present study confirm these conclusions.

Acknowledging these social and demographic variables associated with abusive alcohol consumption allows us to establish a risk profile. Certainly, these variables must not be used instead of the questionnaires developed for diagnosis. On the other hand, thorough investigation of all of patients 
who come to the emergency room may not be possible or even necessary. Recognizing this risk profile may alert the medical staff to patients at high risk for alcoholism, make using the diagnostic instrument more effective, and consequently, increase the predictive value of the applied test, although this risk factor-based approach would have to be tested and validated in future studies.

The under-recording of cases of alcoholism at hospital admission is a problem that has been described previously. ${ }^{8-11,14-16}$ In this study, only $20 \%$ of the actual cases, as identified by AUDIT, were identified by the medical team during emergency room treatment. Although males were most frequently identified as being alcoholics, which might indicate that the medical staff looks more actively at this subgroup for alcohol abuse, the overall frequency of identification was low, even among these higher risk patients. Furthermore, most $(70.6 \%)$ of the cases diagnosed by the medical team did not meet the alcoholism criteria established in our study and in others that relied on AUDIT.

Many factors have been associated with the low identification indexes for alcoholic patients by medical staff. Lack of knowledge and communication problems involving alcohol consumption are barriers that make it more difficult for medical personnel to arrive at a correct diagnosis. ${ }^{33}$ Rowland et al. concluded that physicians did not consider it a priority to ask patients about their alcohol consumption habits. ${ }^{34}$ Lack of discussion in medical school concerning patients' potential psychoactive substance consumption is also a major cause of problems in diagnosing alcoholism. ${ }^{8}$

One of the consequences of this high rate of underdiagnosis is that the indication for intervention occurs only when alcohol consumption leads to somatic diseases, social problems or severe withdrawal symptoms. ${ }^{35}$ Under these circumstances, interventions are less successful. Screening for alcoholism, especially using standardized instruments, not only identifies a much larger number of patients but it also identifies them at an earlier stage.

This study has a few limitations. First, it was developed at a single hospital, which might make it difficult to extend the results to other hospitals and/or regions. However, all of the presented data are consistent with previously published reports in the literature, and it is likely that these results are not specific characteristics of the population at this hospital. Second, we cannot exclude an interobserver variability during the interview in the emergency department. Third, we consider AUDIT the gold standard for the diagnosis of alcoholism, and, therefore, its limitations should be taken into account when interpreting the results. Finally, the evaluation of identification by the medical team was based only on information in the medical record. Rumpf et al. showed that, when identification of alcoholics by the physicians is performed only from the medical records, it is less effective than when evaluated by a direct interview. ${ }^{16}$ On the other hand, another study found that the failure to detect patients with possible alcohol-related problems largely occurs as a result of a lack of investigation and diagnosis, and not because of incomplete records. ${ }^{9}$

\section{CONCLUSIONS}

It is concluded that alcoholism has not been adequately investigated and diagnosed on hospital admission, and that this opportunity for possible intervention is often lost. A few social and demographic factors could provide the physicians with warning signs and, used together with a standardized diagnostic instrument, could significantly improve the identification of alcoholic patients. This is the first step to reduce alcohol consumption and offer appropriate treatment to these patients. An aspect that is beyond the scope of this study is the need to better educate medical students, residents and other hospital professionals on the risk factors and signs of alcoholism to correct this flaw in accurately diagnosing alcoholism. Moreover, the implementation of programs designed to reduce patients' alcohol consumption at early stages may reduce the costs and social and personal consequences associated with alcohol abuse.

\section{REFERENCES}

1. Kessler RC, Mcgonagle KA, Zhao S, Nelson CB, Hughes M, Eshleman $\mathrm{S}$, et al. Lifetime and 12-month prevalence of DSM-III-R psychiatric disorders in the United States: results from the National Comorbidity Survey. Arch Gen Psychiatry. 1994;51:8-19.

2. Almeida Filho LM, Mari JJ, Coutinho E. Estudo multicêntrico de morbidade psiquiátrica em áreas urbanas brasileiras (Brasília, São Paulo, Porto Alegre). Rev ABP-APAL. 1992;14:38-42.

3. World Health Organization. The World Health Report 1999: Making a Difference. Geneva: World Health Organization.
4. Single E, Rehm J, Robson L, Truong MV. The relative risks and etiologic fractions of different causes of death and disease attributable to alcohol, tobacco and ilicit drug use in Canada. CMAJ. 2000;162:1669-75.

5. US Department of Health and Human Services. Tenth Special Report to Congress on Alcohol and Health. Bethesda, Md: US Dept of Health and Humans Services; 2000.

6. Ryder D, Lenton S, Harrison S, Dorricot J. Alcohol-related problems in a general hospital and a general active: screening and the preventive paradox. Med J Austral. 1988;149:355-60. 
7. Figlie NB, Pillon SC, Dunn J, Laranjeira R. The frequency of smoking and problem drinking among general hospital inpatients in Brazil - using the AUDIT and Fagerström questionnaires. Sao Paulo Med J/Rev Paul Med. 2000;118:139-45.

8. Schneekloth TD, Morse RM, Herrick LM, Suman VJ, Offord KP, Davis LJ. Point prevalence of alcoholism in hospitalized patients: continuing challenges of detection, assessment, and diagnosis. Mayo Clin Proc. 2001;76:460-6.

9. Rosa AA, Gonçalves SC, Stefani SD, Martins OS, Rosa DD, Hunsche A. Percepção e registro de abuso de álcool e de doenças relacionadas num hospital geral universitário. Rev Ass Med Brasil. 1998;44:335-339.

10. Moore RD, Bone LR, Geller G, Mamon JA, Stokes EJ, Levine DM. Prevalence, detection, and treatment of alcoholism in hospitalized patients. JAMA. 1989;261:403-7.

11. Chen $\mathrm{CH}$, Chen WJ, Cheng ATA. Prevalence and identification of alcohol use disorders among nonpsychiatric inpatients in one general hospital. Gen Hosp Psychiatry. 2004;26:219-25.

12. Horn K,Leontieva L, Williams JM, Furbee PM, Helmkamp JC, Manley III WG. Alcohol problems among young adult emergency department patients: making predictions using routine sociodemographic information. J Crit Care. 2002;17:212-20.

13. Smothers BA, Yahr HT, Sinclair MD. Prevalence of current DSM-IV alcohol use disorders in short-stay, general hospital admissions, United States, 1994. Arch Intern Med. 2003;163:713-9.

14. Bush B, Shaw S, Cleary P, Delbanco T, Aronson M. Screening for alcohol abuse using the CAGE questionnaire. Am J Med. 1987;82:231-5.

15. Hearne R, Connolly A, Sheehan J. Alcohol abuse: prevalence and detection in a general hospital. J R Soc Med. 2002;95:84-7.

16. Rumpf HJ, Bohlmann J, Hill A, Hapke U, John U. Physicians' low detection rates of alcohol dependence or abuse: a matter of methodological shortcomings? Gen Hosp Psychiatry. 2001;23:133-7.

17. Seppa K, Makela R. Heavy drinking in hospital patients. Addiction. 1993; 88:1377-82.

18. Bien TH, Miller WR, Tonigan JS. Brief interventions for alcohol problems: a review. Addiction. 1993, 88:315-35.

19. Gentilello LM, Rivara FP, Donovan DM, Jurkovich GJ, Daranciang E, Dunn CW. Alcohol interventions in a trauma center as a means of reducing the risk of injury recurrence. Ann Surg. 1999;230:473-83.

20. Saunders JB, Aasland OG, Babor TF, De la Fuente JR, Grant M. Development of the Alcohol Use Disorders Identification Test (AUDIT): WHO Collaborative Project on Early Detection of Persons with Harmful Alcohol Consumption. Addiction. 1993;88:791-804.
21. Mendez EB, Lima MS, Olinto MTA, Farrel M. Uma versão brasileira do AUDIT (Alcohol Use Disorders Identification Test). Pelotas: Universidade Federal de Pelotas, 1999.

22. Bohn MJ, Babor TF, Kranzler HR. The Alcohol Disorder Identification Test (AUDIT): validation of a screening instrument for use in medical setting. J Stud Alcohol. 1995;56:423-32.

23. Conigrave KM, Hall WD, Saunders JB. The AUDIT questionnaire: choosing a cut-off score. Addiction. 1995;90:1349-56.

24. Seppa K, Makela R, Sillanaukee P. Effectiveness of the Alcohol Use Disorder Identification Test in occupational health screening. Alcohol Clin Exp Res. 1995;19:999-1003.

25. Isaacson JH, Butler R, Zacharek M, Tzelepis A. Screeening with Alcohol Use Disorder Identirfication Test (AUDIT) in a inner city population. J Gen Intern Med. 1994;9:550-3.

26. Fleming MF, Barry KL, Manwell LB, Johnson K, London R. Brief physician advice for problem alcohol drinkers. JAMA. 1997;277:10391045.

27. Babor TF, Ritson EB, Hodgson RJ. Alcohol-related problems in the primary health care setting: a review of early intervention strategies. Br J Addict. 1986;81:23-46.

28. Guarnieri M. Brief physician advice for problem alcohol drinkers: a randomized controlled trial in community-based primary care practices. Comment. JAMA. 1997;278:1059.

29. Friedman GD, Tekawa I, Klastky AL, Sidney S, Armstrong MA. Alcohol drinking and cigarette smoking: an exploration of the association in middle-aged men and women. Drug Alcohol Depend. 1991;27:28390 .

30. York JL, Hirsch JA. Drinking patterns and health status in smoking and nonsmoking alcoholics. Alcohol Clin Exp Res. 1995;19:666-73.

31. Batel P, Pessione F, Maitre C, Rueff B. Relationship between alcohol and tobacco dependencies among alcoholics who smoke. Addiction. 1995, 90:977-80.

32. Toneatto A, Sobell LC, Sobell MB, Kozlowski LT. Effect of cigarette smoking on alcohol treatment outcome. J Subst Abuse. 1995;7:24552.

33. Clark WD. Alcoholism: blocks to diagnosis and treatment. Am J Med. 1981;71:275-85.

34. Rowland N, Maynard A, Beveridge A, Kennedy P, Wintersgill W, Stone W. Doctors have no time for alcohol screening. BMJ. 1987;295:95-6.

35. Hapke U, Rumpf HJ, John U. Differences between hospital patients with alcohol problems referred for counseling by physicians' routine clinical practice versus screening questionnaires. Addiction. 1998;93:177785 . 